\title{
Galactose-1-Phosphate Uridyltransferase Measurement
}

National Cancer Institute

\section{Source}

National Cancer Institute. Galactose-1-Phosphate Uridyltransferase Measurement. NCI

Thesaurus. Code C81251.

The measurement of the galactose-1-phosphate uridyltransferase in a biologic specimen. 